\section{Dieldrin exposure and vigilance behavior In sheep'}

B. E. SANDLER, G. A. VAN GELDER, D. D. ELSBERRY, G. G. KARAS, and W. B. BUCK, Iowa State University, Ames, Iowa 50010

Sheep exposed to a daily oral dose of $20 \mathrm{mg}$ dieldrin per $\mathrm{kg}$ body weight exhibited a large decrement in the performance of a vigilance task. Three of four sheep recovered their preexposure response levels within 10 days following the termination of exposure. Reexposure of these three animals to $5 \mathrm{mg}$ dieldrin per $\mathrm{kg}$ body weight also resulted in a response decrement.

The widespread use of chlorinated hydrocarbon insecticides has resulted in increased human and animal exposure to these agents. However, little is known of the subtle behavioral effects of these agents. Large doses produce a number of symptoms of clinical toxicity which include hypersensitivity, muscular fasciculations, and clonic-tonic seizures. Death may result from a sufficiently large dose. Alterations of the electroencephalogram (EEG) following exposure have also been reported Van Gelder et al (1968) have reported the occurrence of high voltage $(200-300 \mu \mathrm{V})$ slow-wave $(3-5 \mathrm{~Hz})$ EEG activity in sheep following exposure to dieldrin, a chlorinated hydrocarbon insecticide. There is evidence that this type of EEG activity is associated with a decrement in the performance of a vigilance task (Mirsky \& Cardon, 1962; Mirsky \& Van Buren, 1965). Because of the similarity of the EEG changes which are associated with a vigilance decrement and those found in sheep following dieldrin effect of dieldrin on vigilance behavior in sheep.

\section{SUBJECTS}

The Ss were four experimentally naive female yearling cross-bred sheep. They were maintained at approximately $85 \%$ of their ad lib weights.

\section{APPARATUS}

An operant feeding device suitable for use with sheep was constructed. The apparatus has been described in detail elsewhere (Sandler et al, 1969). It consisted of a food hopper connected by an electric clutch to a shaft rotating constantly at $40 \mathrm{rpm}$. A bar-press caused the clutch to engage and the food hopper was rotated approximately $90 \mathrm{deg}$ to a horizontal position and was mechanically latched. When the hopper came up and latched, contact with a (Hoogendam et al, 1963; Prior, 1963). exposure it was decided to investigate the commutator was broken, thus disengaging the clutch. Activation of a solenoid released the latching mechanism and dropped the hopper. The apparatus was under program control. The operant chamber was rectangular and measured $143 \times 81 \times 96$ in. An air conditioner in the operant chamber ran continuously and served to mask extraneous noises and to maintain a relatively constant temperature. The manipulandum was a floor-mounted, normally closed switch that measured $12 \times 12$ in. It was located 16 in. to the right of the food hopper. A signal generator was used to produce a $5 \cdot \mathrm{KHz}$ tone, which was then amplified to $6 \mathrm{~dB}$ and presented through a speaker in the operant chamber.

\section{PROCEDURE}

The sheep were trained to bar-press using standard shaping procedures. After the bar-pressing response had been acquired, training was begun with a discriminative stimulus $\left(\mathrm{S}^{\mathrm{D}}\right)$. The $\mathrm{S}^{\mathrm{D}}$ (a 5-KHz, 6-dB tone) was turned on and remained on until $S$ bar-pressed. The bar-press resulted in the termination of the tone and the presentation of the food hopper for $3.5 \mathrm{sec}$. After termination of the tone, a $30-\mathrm{sec}$ period during which no responses were made had to occur before the next tone presentation. The duration of the tone was gradually reduced until $S$ reliably responded within $5 \mathrm{sec}$ to a $0.1 \cdot \sec$ tone presentation.

Upon completion of training, bilateral recording electrodes were surgically
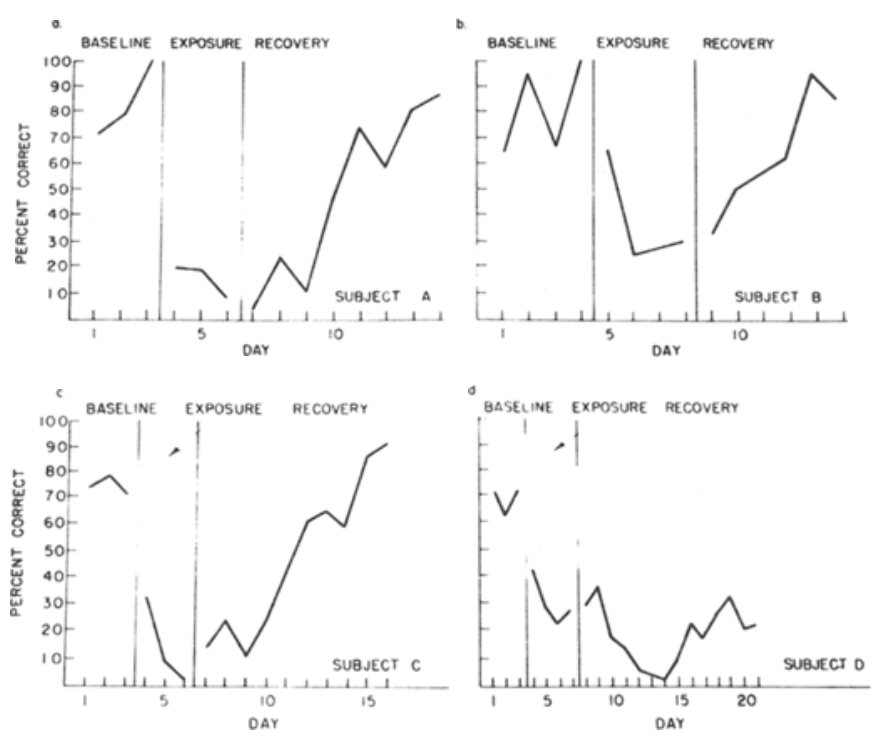

Fig. 1. Performance of Ss A, B, C, and D during baseline, exposure, and recovery periods. Exposure level was $20 \mathrm{mg}$ technical dieldrin per $\mathrm{kg}$ body weight. data were collected. During this baseline period Ss received a daily oral placebo capsule and 50 tone presentations (trials) per day. When the control data had been collected the sheep were exposed to a daily oral dose of $20 \mathrm{mg}$ technical dieldrin per $\mathrm{kg}$ body weight (b.w.). During the exposure period Ss were given two blocks of 50 trials each per day. The first block was given $2 \mathrm{~h}$ after the daily exposure, the second $7 \mathrm{~h}$ postexposure. Exposure was continued for 2 days following the day on which highvoltage, slow-wave EEG activity first occurred. Exposure was then discontinued and Ss were given 50 trials per day until they were responding at their preexposure levels. At the conclusion of this recovery period Ss began a 1-week period during which they were not tested. Beginning with the second week Ss were given $\mathbf{5 0}$ trials per day. During the last 3 days of this week Ss were given oral place bo capsules and control behavioral data were collected. Ss were then exposed to a daily oral dose of 5-mg technical dieldrin per $\mathrm{kg}$ b.w. The Ss were tested for the behavioral decrement and recovery using the procedure described above.

At the conclusion of the experiment $S$ s were euthanitized and post mortem examinations were conducted to determine if any gross pathological changes had occurred in the brain.

\section{RESULTS}

Hyperirritability was observed in all Ss following exposure and reexposure. This implanted on the dura mater over the frontal, temporal, and occipital cortex. Following a 1-week postoperative recovery period, Ss were given additional training. When they were responding at a stable level 3 or 4 days of control EEG and behavioral

Psychon. Sci., 1969, Vol. 15 (5) 
was the only sign of clinical toxicity observed throughout the experiment. Highvoltage, slow-wave EEG activity occurred in all Ss on either the first or second day following exposure. As exposure continued the duration of these changes and the frequency of their occurrence increased. These EEG changes occurred while Ss were in their living area, but never occurred while Ss were in the operant chamber.

During the exposure periods Ss were given two blocks of 50 trials each per day to determine whether dieldrin exposure resulted in differential performance within days. Since inspection of the data revealed that this was not the case, the mean performance within days during the exposure periods constitutes the data reported in the figures. Figure 1 (a-d) presents the data from the first exposure $(20 \mathrm{mg} / \mathrm{kg})$. There was a large decrement in the mean per cent of responses to tone presentations during the exposure period. This decrement occurred in all Ss and ranged from $76 \%$ (Fig. 1a) to $38 \%$ (Fig. 1d). Three of four Ss recovered their preexposure response levels within $\mathbf{1 0}$ days after termination of dieldrin exposure. The fourth $S$ did not recover its preexposure response level (Fig. 1d). No pathological changes were found in the brain of this sheep.

Figure $2(a-c)$ presents the results of reexposure to 5 -mg dieldrin per $\mathrm{kg}$. A performance decrement occurred in all $\mathrm{Ss}$ and ranged from 55\% (Fig. $2 a$ ) to $21 \%$ (Fig. 2b). Two of the sheep recovered their preexposure levels 3 days after exposure was terminated. The third S (Fig. 2a) did not recover its preexposure level. Post mortem examination of this $S$ revealed an abscess in the left cerebral hemisphere. No pathological changes were found in the other Ss.

\section{DISCUSSION}

There is evidence that the observed decrement was not the result of a decrease in auditory sensitivity. On many trials which did not result in a bar-press Ss did, however, show an orienting response to the tone. This response consisted of the perking up of the head and ears and looking around the test chamber. In addition, the presentation of the tone often resulted in an arousal response on Ss' EEG record.

There is also evidence that the performance decrement was not the result of a decrease in the attractiveness of the food reward. On those trials in which Ss gained access to food they ate eagerly. Furthermore, when Ss were given access to food in their living area they ate eagerly and completely.

The reexposure of the Ss to a level of
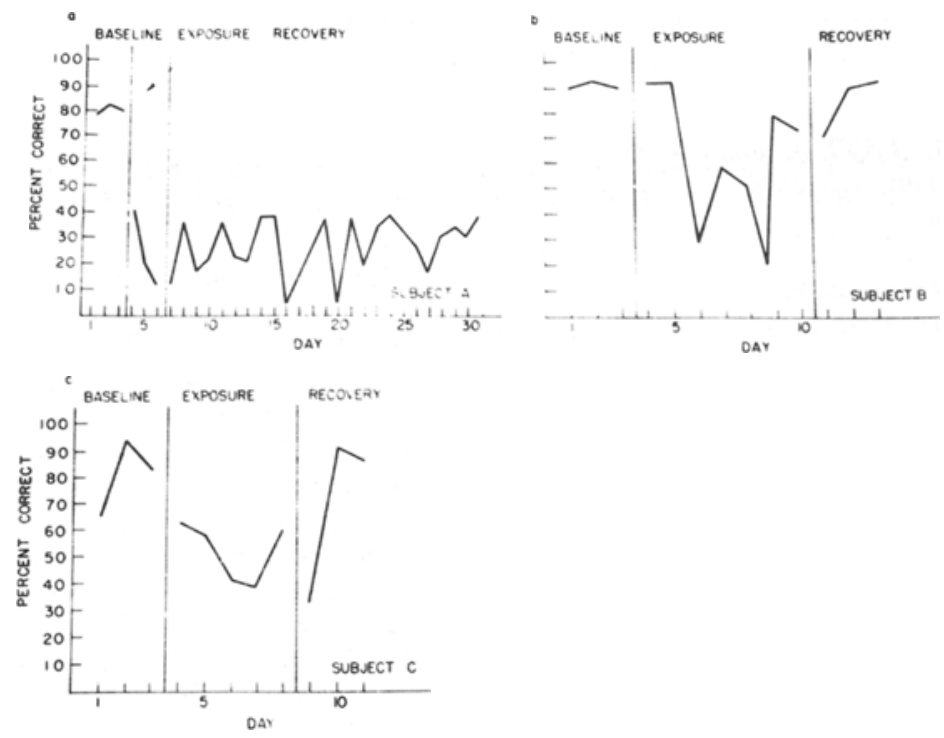

Fig. 2. Performance of Ss A, B, and C during baseline, exposure, and recovery periods. Exposure level was $5 \mathrm{mg}$ technical dieldrin per kg body weight.

dieldrin lower than that originally given indicated that a vigilance decrement would be likely to result from lower exposure levels. However, it must be realized that although the Ss were responding at their normal levels prior to reexposure, there undoubtedly were dieldrin residues present in their bodies. Thus there were carry-over effects in the reexposure period and it is not possible to state that the effects seen in these Ss would occur in Ss previously unexposed to dieldrin. The data are useful, however, in that they provide some information about the effects of lower-level exposure.

This study was designed to test for a decrement in vigilance performance, not to discover the mechanism mediating the decrement. However, it is possible to speculate concerning the areas of the brain which are most likely to be involved and the reasons for the decrement in performance.

Research conducted in our laboratory has found that dieldrin residue levels in sheep were significantly higher in the brain stem than elsewhere in the brain. Landsdell \& Mirsky (1964) and Mirsky et al (1960) have argued that the maintenance of attention in man is dependent upon the normal functioning of the central subcortical structures. Thus, to the extent that dieldrin interferes with the normal functioning of these structures, decrements in vigilance behavior would be expected.

\section{REFERENCES}

HOOGENDAM, I., VERSTEEG, J. P. \&
De VLIEGER, M. Electroencephalograms in insecticide toxicity. Archives of Environmental Health, 1963, 4, 92-100.

LANDSDELL, H., \& MIRSKY, A. F. Attention in focal and centrencephalic epilepsy. Experimental Neurology, 1964, 9, 463-469.

MIRSKY, A. F., \& CARDON, P. V. A comparison of the behavioral and physiological change accompanying sleep deprivation and chlorpromazine administration in man. Electroencephalography \& Clinical Neurophysiology, 1962, 14, 1-10.

MIRSKY, A. F. PRIMAC, D. W., MARSAN, C. A., ROSVOLD, H. E., \& STEVENS, J. R. A comparison of psychological test performance of patients with focal and nonfocal epilepsy. Experimental Neurology, 1960, 2, 75-89.

MIRSKY, A. F., \& VAN BUREN, J. M. On the nature of the "absence" in centrencephalic epilepsy: A study of some behavioral, electroencephalographic and autonomic factors. Electroencephalography \& Clinical Neurophysiology, 1965, 18, 334-348.

PRIOR, P. F. EEG findings in aldrin intoxication. Electroencephalography \& Clinical Neurophysiology, 1963, 15, 915 .

SANDLER, B. E., VAN GELDER, G. A., KARAS, G. G., \& BUCK,W. B. An operant feeding device for sheep. Journal of the Experimental Analysis of Behavior, in press.

VAN GELDER, G. A.. SANDLER, B. E., BUCK, W. B., MALAND, J. B., \& KARAS, G. G. Behavioral and electrophysiological effects of dieldrin in sheep. Paper presented at the meeting of the Inter-American Conference on Oicupational Medicine, Miami, August 1968.

\section{NOTE}

1. This research was supported by Grant No. 5 R01 ES00122 from the Division of Environmental Health. National Institu tes of Health, and by Contract No. PH86-66-Neg-26 from the Communicable Disease Center. 